\title{
Wait times, resource use and health-related quality of life across the continuum of care for patients referred for total knee replacement surgery
}

\author{
Yekaterina Lebedeva, MSc \\ Laura Churchill, PhD \\ Jacquelyn Marsh, PhD \\ Steven J. MacDonald, MD \\ J. Robert Giffin, MD \\ Dianne Bryant, PhD
}

Accepted Apr. 22, 2020

\section{Correspondence to:}

Dianne Bryant

School of Physical Therapy

Western University

Elborn College

1201 Western Rd

London ON N6G 1H1

Dianne.bryant@uwo.ca

DOI: 10.1503/cjs.003419

\begin{abstract}
Background: The escalating socioeconomic burden of knee osteoarthritis $(\mathrm{OA})$ underscores the need for innovative strategies to reduce wait times for total knee arthroplasty (TKA). The purpose of this study was to evaluate resource use, costs and health-related quality of life (HRQoL) across the continuum of care for patients with knee OA.

Methods: This was a prospective study of 383 patients recruited from a high-volume teaching hospital at different stages of care (referral, consultation and presurgery). Outcomes included health care resource use; costs captured from the health care payer, private sector and societal perspectives; HRQoL measured using the Western Ontario and McMaster Universities Osteoarthritis Index, the 12-Item Short Form Health Survey, and EuroQoL 5-Dimension 5-Level tool; wait times; and the proportion of referrals deemed suitable candidates for surgery.

Results: The most commonly used conservative treatments were pharmacotherapy, exercise and lifestyle modification. Forty percent of patients referred for TKA were deemed not to be suitable candidates for surgery. The greatest proportion of costs was borne by the patient or private insurer; a small proportion was borne by the public payer. Across all stages of care, more than $60 \%$ of the total costs was attributed to productivity losses. HRQoL remained relatively stable throughout the waiting period (mean wait time from referral to TKA $13.2 \mathrm{mo}$ ) but improved postoperatively.
\end{abstract}

Conclusion: The suboptimal primary care management of knee OA calls for the development of innovative models of care. This study may provide valuable guidance on the design and implementation of a new online educational platform to improve referral efficiency and expedite wait times for TKA.

Contexte : Le fardeau socioéconomique croissant de l'arthrose du genou rappelle que nous avons besoin de stratégies novatrices afin de réduire les temps d'attente pour l'arthroplastie totale du genou (ATG). Le but de cette étude est d'évaluer l'utilisation des ressources, les coûts et la qualité de vie liée à la santé (QVLS) dans tout le continuum des soins pour les patients souffrant d'arthrose du genou.

Méthodes : Cette étude prospective a porté sur 383 patients recrutés dans un établissement d'enseignement fort achalandé, qui en étaient à différentes étapes du continuum de soins (demande de consultation, consultation et préchirurgie). Les paramètres incluaient l'utilisation des ressources en santé, les coûts du point de vue sociétal et des régimes d'assurance maladie publics et privés, la QVLS mesurée au moyen de l'indice WOMAC (Western Ontario and McMaster Universities Osteoarthritis Index), du questionnaire Short Form Health Survey en 12 points et de l'outil EuroQoL appliqué à 5 dimensions et à 5 niveaux, les temps d'attente, et la proportion de demandes de consultation concernant des patients considérés comme de bons candidats à la chirurgie.

Résultats : Les traitements conservateurs les plus utilisés étaient la pharmacothérapie, l'exercice et les modifications à l'hygiène de vie. Quarante pour cent des patients adressés en consultation pour ATG ont été considérés comme de bons candidats à la chirurgie. La plus grande part des coûts a été assumée par le patient ou un assureur privé; une faible part des coûts a été assumée par le régime public. À toutes les étapes du continuum, plus de $60 \%$ des coûts totaux ont été attribués à des pertes de productivité. La QVLS est demeurée relativement stable tout au long de la période d'attente (temps d'attente moyen entre la consultation et l'ATG, 13,2 mois) mais s'est améliorée après la chirurgie.

Conclusion : La prise en charge sous-optimale de l'arthrose du genou en soins primaires rappelle qu'il est nécessaire d'établir des modèles de soins novateurs. Cette étude pourrait faciliter la mise au point et l'application d'une nouvelle plateforme éducative en ligne pour améliorer l'efficience des demandes de consultation et abréger les temps d'attente pour l'ATG. 
$\mathbf{T}$ otal knee arthroplasty (TKA) is a highly costeffective procedure for patients with end-stage knee osteoarthritis $(\mathrm{OA})$ who are experiencing debilitating pain and functional impairment despite nonoperative treatment. ${ }^{1}$ According to a 2017 report from the Fraser Institute, the median wait times between referral for TKA and the initial surgical consultation $(4.5 \mathrm{mo}$ ) and between referral and surgery $(10.4 \mathrm{mo})$ are the longest among all procedures. ${ }^{2}$ Not only is the proportion of Canadians older than 65 years growing, but so is the demand for TKA across all age groups. ${ }^{3-5}$

The sizable socioeconomic impact of waiting for TKA underscores the importance of developing innovative strategies to minimize wait times. Studies have shown that most patients experience a significant decline in health-related quality of life (HRQoL) while waiting for TKA $^{6}$ and that prolonged wait times are associated with lower postoperative HRQoL. ${ }^{7,8}$ Furthermore, poorer health status before surgery was found to be a significant predictor of worse outcomes and higher costs postoperatively. ${ }^{9-12}$ Osteoarthritis-related costs have also been reported to increase with disease severity. ${ }^{13,14}$ A large proportion of these costs can be attributed to losses in patient and caregiver productivity, as an estimated $32 \%$ of patients waiting to undergo joint arthroplasty are unable to engage in their daily activities. ${ }^{15,16}$

When the demand for elective procedures exceeds the supply, wait times generally arise and serve to ration access to services, particularly within publicly funded health care systems. ${ }^{17}$ However, wait times for TKA vary widely not only between, but also within, provinces. ${ }^{18}$ According to the 2014 Wait Time Alliance report, increasing funding alone is an unsustainable strategy for managing wait times; structural changes must also be made at the primary care level. ${ }^{19}$ Primary care providers (PCPs) play a central role in diagnosing knee OA, managing symptoms nonoperatively and deciding whom and when to refer to an orthopedic specialist for surgical treatment. A large proportion of patients referred for TKA are deemed not to be candidates for surgery ${ }^{20-22}$ despite the existence of numerous clinical practice guidelines for the primary care management of knee OA. ${ }^{23-25,34-36}$ Studies have consistently shown wide variability in PCPs' perceptions regarding nonoperative treatments for knee $\mathrm{OA}$ and indications for TKA, ${ }^{24-26}$ highlighting the need for clear recommendations to support consistent clinical decision-making in primary care.

Although Health Canada developed wait time benchmarks for TKA and announced that wait time reduction was a key priority, no strategy had been proposed at the federal level. ${ }^{27}$ As a result, provinces have piloted and implemented a variety of wait time management strategies, including physician directories, presurgical screening and prioritization tools, and central intake and assessment clinics. ${ }^{17,28-30}$ However, little is known about their sustainability and long-term implications.

In a 2014 policy statement, the Canadian Medical Association argued that there is no single optimal method to improve access to specialty care and that a combination of strategies is required. ${ }^{28}$ Although central intake and assessment clinics may reduce unnecessary referrals, they create an additional costly point of contact between primary and specialty care. We propose a new online educational platform as an approach to streamline the referral process and expedite access to TKA for patients who are sufficiently symptomatic, nonresponsive to nonoperative management and willing to undergo surgery. To facilitate decision-making in primary care, the platform will include educational videos that provide patients and referring physicians with evidence-based recommendations on appropriate diagnostic imaging tests, nonoperative treatment options, the surgical procedure and postoperative expectations. Thus, the platform may be implemented on its own or as an adjunct to other wait time management strategies.

To inform the design and implementation of the online educational platform, the purpose of this study was to measure health care resource use (nonoperative treatments and diagnostic imaging tests), costs and HRQoL in patients with knee OA at 5 stages along the continuum of care: (1) before referral, (2) from referral to initial surgical consultation, (3) from the date of inclusion on the surgical wait list to TKA (or, if not scheduled for surgery, from initial consultation to 1 year after consultation), (4) from TKA until 2 years after surgery and (5) approximately 5 years after consultation for patients who were not scheduled for TKA at their initial surgical consultation and were no longer being followed by the orthopedic surgeon.

We also determined the proportion of nonoperative referrals and reported the total wait time in 2 consecutive segments: from referral to initial surgical consultation (WT1) and from the date of inclusion on the surgical wait list to TKA (WT2). The comparison of these outcomes before and after the implementation of the online educational platform will enable us to evaluate its potential to promote the uptake of evidence-based recommendations into primary care practice and ultimately reduce wait times for TKA.

\section{Methods}

\section{Participants}

This was a prospective cohort study conducted between December 2016 and April 2018 at a large teaching hospital in London, Ontario, Canada. The study population consisted of 4 patient groups recruited at 1 of 4 time points: at the time of referral to an orthopedic surgeon 
(new referrals), at the initial surgical consultation (new consults), at the preadmission appointment before TKA (presurgical patients), or approximately 5 years after consultation (long-term follow-up patients deemed not to be eligible for surgery at their first consult). Patients were eligible to participate if they were older than 18 years, had received a diagnosis of knee OA and had been referred to an orthopedic surgeon for consideration of TKA. Exclusion criteria included an inability to provide informed consent or complete study questionnaires in English.

Patients who provided consent were registered into a secure Web-based data management system (EmPower Health Research Inc.) and completed a series of questionnaires at the time of recruitment. Follow-up assessments were conducted electronically or over the phone. New referrals were contacted by phone within a week of receiving their referral request. New consults were recruited in the joint replacement clinic before their first surgical consultation. Presurgical patients were recruited during their preadmission appointment, typically 3-6 weeks before they underwent surgery. Patients who consented to participate completed the questionnaires during their preadmission appointment and then at 1.5 months, at 6 months and subsequently every 3 months until 1 year postoperatively. The long-term follow-up group consisted of patients who were deemed not to be eligible for surgery in a previous study conducted in 2013 and had not undergone knee surgery since then. ${ }^{31}$ These participants completed the questionnaires once, approximately 5 years after that initial consultation. Attempts were made to follow up on missing data via telephone, email or postal mail, where possible. The study was approved by the Research Ethics Board at the University of Western Ontario.

\section{Outcome measures}

Participants completed a questionnaire that captured the use of diagnostic imaging tests and conservative treatments for knee OA, either before referral (for new referrals and new consults) or following initial consultation (for presurgical and long-term follow-up patients). The sections addressing the use of physical, occupational and chiropractic therapies included questions on the types of treatments used, the frequency and duration of the treatment, and whether therapy was recommended but the patient opted out. We also asked longterm follow-up patients to indicate whether they had undergone surgery since their first consult, if surgery was scheduled at the time of data collection or if surgery was recommended but they opted out.

Following the initial surgical consultation, the attending surgeons completed a form in which they classified patients as operative or nonoperative referrals and assigned each case a priority rating: (1) the consult should have occurred sooner (late referral), (2) the consult occurred at the appropriate time (timely referral) or (3) the consult could have waited (early referral).

We measured HRQoL using the Western Ontario and McMaster Universities Osteoarthritis Index (WOMAC), a disease-specific health status tool, and 2 generic measures: the 12-Item Short Form Health Survey (SF-12, version 2) and the EuroQoL 5-Dimension 5-Level (EQ-5D-5L) tool. The WOMAC measures pain, stiffness and physical function and provides an overall score ranging from 0 to 96. The WOMAC has been widely reported to be valid, reliable and responsive among patients with OA. ${ }^{32-34}$ The SF-12 captures 8 domains of health and provides a physical component score (PCS) and a mental component score (MCS) ranging from 0 to 100 . The SF-12 has been shown to be the most valid and responsive generic HRQoL tool for patients undergoing joint arthroplasty. ${ }^{34,35}$ The EQ-5D-5L consists of a 5-item index that provides a utility value from 0 (death) to 1 (perfect health) and a visual analogue scale that measures patientperceived health status on a scale from 0 to 100 .

At 3-month time intervals along the continuum of care, patients reported any costs related to knee OA that they incurred. We captured a wide range of direct and indirect costs to reflect the health care payer; patient or private insurer; and societal perspectives. The health care payer perspective considers only direct governmentfunded medical costs, whereas the societal perspective captures all direct and indirect costs, including out-ofpocket and productivity costs. The 3 -month cost recall questionnaire captured direct medical costs related to knee OA (diagnostic tests, procedures, physician visits, hospital admissions and medications for patients over the age of $65 \mathrm{yr}$ or on disability insurance), out-of-pocket costs (e.g., supplies and equipment, transportation, parking) and productivity costs (i.e., time lost from paid work and leisure).

Multiple data sources were used to obtain the unit cost for each health care resource item and estimate the total mean cost per patient for a given 3 -month period. Costs of physician visits, diagnostic tests, medical procedures and inpatient hospital admissions were obtained from the Ontario Schedule of Benefits for Physician Services $^{36}$ and the Patient Cost Estimator tool developed by the Canadian Institute for Health Information. ${ }^{37}$ The costs of allied health services covered by a private insurer were self-reported, whereas those funded by the public payer were assumed to equal a quarter of the annual funding allotted for an episode of care (i.e., \$312 for diagnosis-specific, time-limited services provided to a given patient per year). ${ }^{38} \mathrm{We}$ obtained the unit costs of medications from the Ontario Drug Benefit Formulary and added the appropriate markup and dispensing fees. ${ }^{39}$ Productivity costs were 
estimated using the human capital approach. ${ }^{40}$ Time lost from paid work was valued at the average hourly wage in Ontario. ${ }^{41}$ Leisure and informal caregiver time was valued at the current minimum wage. ${ }^{42}$ All costs were adjusted to 2018 Canadian dollars.

We used descriptive statistics (means and standard deviations for continuous variables, and frequencies and percentages for categorical variables) to summarize HRQoL and cost data by stage of care: (1) before referral, (2) from date of inclusion on the surgical wait list to TKA (presurgery) and (3) from initial consultation during which patients were not booked for TKA but were followed for approximately 5 years after consultation (long-term).

\section{Results}

Of the 590 patients screened for eligibility, 383 (58 new referrals, 192 new consults, 119 presurgical patients and 14 long-term follow-up patients) were enrolled in the study and completed the baseline questionnaires (Figure 1). Demographic characteristics were similar across patient groups (Table 1). The mean wait time from referral to initial surgical consultation was 3.6 (range 0.1-18.4) months, and the mean wait time from consultation to TKA was 9.6 (range 1.4-22.2) months.

\section{Health care resource use}

Pharmacotherapy, exercise and lifestyle or activity modification were consistently the most common nonoperative treatments used throughout the continuum of care (Table 2). Before their referral, $17 \%$ of patients who had physiotherapy (21 of 123) discontinued this treatment sooner than recommended, citing pain and unaffordability as the driving reasons for discontinuation. Across all stages of care, the majority of patients were able to report their diagnostic imaging test results. More than half of new patients $(57 \%$; 142 of 248 patients who reported using nonoperative treatments before referral) received prereferral intra-articular joint injections, $38 \%$ of which were administered by a PCP. Twentyone percent of these patients (52 of 248) underwent prereferral magnetic resonance imaging (MRI) examinations in addition to plain radiography.

\section{Costs}

At each follow-up, a considerable proportion of the total (societal) cost was incurred by the patient or the private insurer or both $(>85 \%$ during WT1, > 40\% during WT2 and $>60 \%$ at the long-term follow-up;

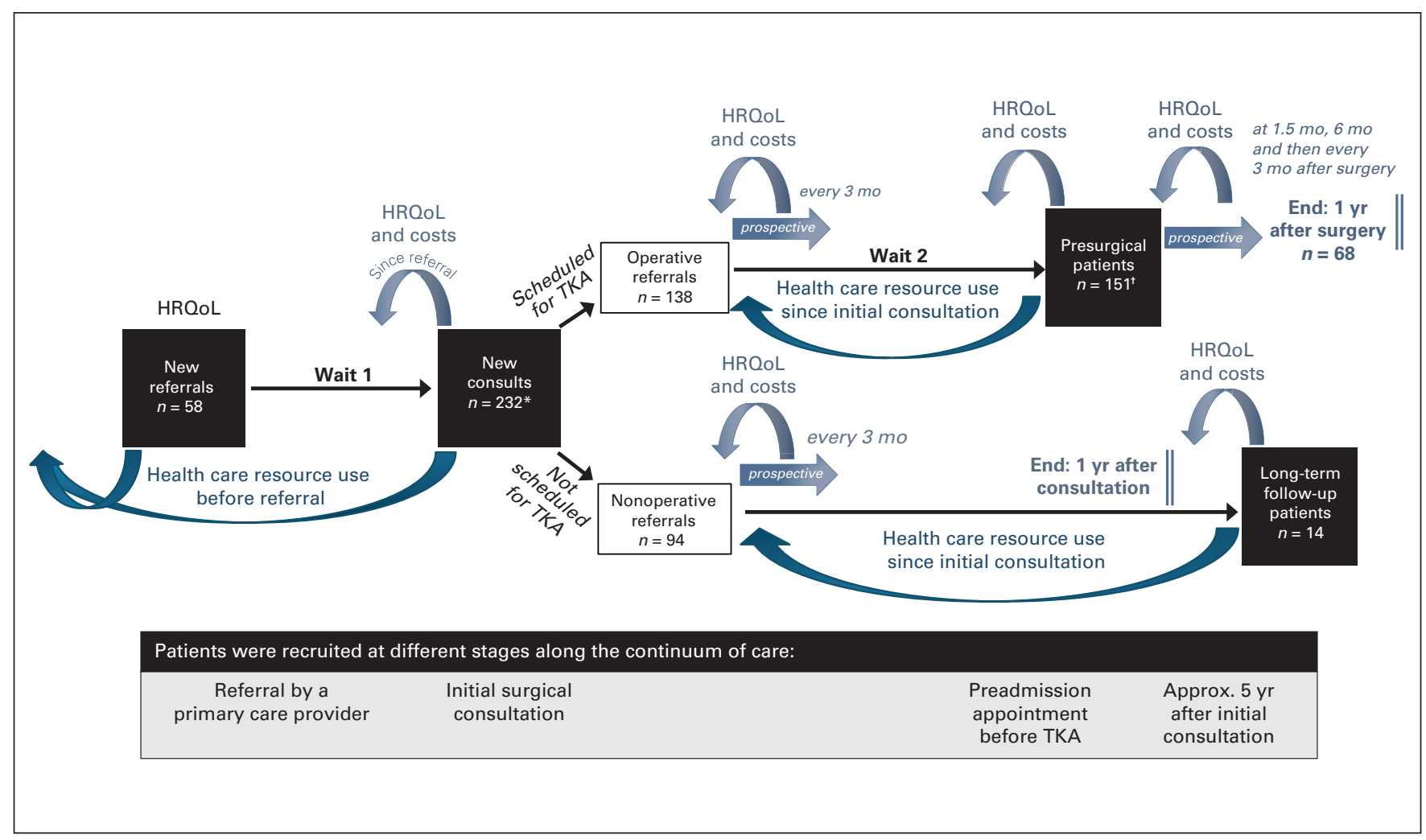

Fig. 1. Study flow. HRQoL = health-related quality of life; TKA = total knee arthroplasty. *The new consults group consisted of 189 new consults and 43 new referrals. TThe presurgical group consisted of 119 presurgical patients and 32 new consults who had undergone surgery at the time of data analysis. 
Table 1. Demographic characteristics of study participants

\begin{tabular}{|c|c|c|c|}
\hline \multirow[b]{2}{*}{ Characteristic } & \multicolumn{3}{|c|}{ No. (\%) of patients; ${ }^{*}$ group } \\
\hline & $\begin{array}{c}\text { New referrals } \\
n=58^{*}\end{array}$ & $\begin{array}{c}\text { New consults } \\
n=192^{*}\end{array}$ & $\begin{array}{c}\text { Presurgical } \\
n=119\end{array}$ \\
\hline Age, $y r$, mean $\pm S D$ & $68.3 \pm 9.3$ & $66.0 \pm 9.5$ & $66.8 \pm 8.9$ \\
\hline Sex, female & $31(53.4)$ & $116(60.4)$ & $68(56.7)$ \\
\hline Body mass index, $\mathrm{kg} / \mathrm{m}^{2}$, mean $\pm \mathrm{SD}$ & $31.4 \pm 7.9$ & $32.0 \pm 8.3$ & $34.9 \pm 7.9$ \\
\hline Dominant side, right & $51(87.9)$ & $171(89.1)$ & $114(95.0)$ \\
\hline Affected knee, right & $25(43.1)$ & $103(53.6)$ & $60(50.0)$ \\
\hline Contralateral symptoms & $41(70.7)$ & $157(81.8)$ & $80(66.7)$ \\
\hline Previous joint arthroplasty & $6(10.3)$ & $19(9.9)$ & 40 (33.3) \\
\hline Global rating of knee pain $(0-10)$, mean $\pm S D$ & $6.6 \pm 2.3$ & $5.4 \pm 2.4$ & $5.3 \pm 2.2$ \\
\hline PASS 2, yes & $23(39.7)$ & $96(50.0)$ & N/A \\
\hline \multicolumn{4}{|l|}{ Living arrangements } \\
\hline Alone & $12(20.7)$ & $52(27.1)$ & $25(20.8)$ \\
\hline With spouse or partner & $42(72.4)$ & $108(56.3)$ & $78(65.0)$ \\
\hline With other family member(s) & $3(5.2)$ & 32 (16.8) & $17(14.2)$ \\
\hline Residential care facility & $1(1.7)$ & 0 & 0 \\
\hline Stairs at home, yes & 49 (84.5) & 137 (71.6) & $70(58.3)$ \\
\hline \multicolumn{4}{|l|}{ Employment status ${ }^{-}$} \\
\hline Retired & $32(55.2)$ & $105(55.3)$ & $75(63.0)$ \\
\hline Full time & $11(19.0)$ & 49 (25.8) & $17(14.2)$ \\
\hline Part time & $6(10.3)$ & $12(6.3)$ & $12(10.0)$ \\
\hline Self-employed & $2(3.4)$ & $2(1.1)$ & $4(3.4)$ \\
\hline Volunteer & $1(1.7)$ & $2(1.1)$ & $1(0.8)$ \\
\hline Long-term disability & 0 & $8(4.2)$ & $4(3.3)$ \\
\hline Temporary sick leave & 0 & $5(2.6)$ & $4(3.3)$ \\
\hline Unemployed & 0 & $3(1.6)$ & 0 \\
\hline Other & 0 & $4(2.1)$ & $2(1.7)$ \\
\hline \multicolumn{4}{|l|}{ Annual household incomeł } \\
\hline$<\$ 20000$ & $5(8.6)$ & 29 (15.3) & $12(10.0)$ \\
\hline$\$ 20000-\$ 40000$ & $13(22.4)$ & 49 (25.8) & $24(20.8)$ \\
\hline$\$ 40000-\$ 60000$ & $7(12.1)$ & 29 (15.3) & $24(20.0)$ \\
\hline$\$ 60000-\$ 80000$ & $12(20.7)$ & $26(13.7)$ & 16 (13.3) \\
\hline$\$ 80000-\$ 100000$ & $3(5.2)$ & $18(9.5)$ & $24(20.0)$ \\
\hline$>\$ 100000$ & $11(19.0)$ & $31(16.2)$ & 14 (11.7) \\
\hline Undisclosed & $2(3.4)$ & $8(4.2)$ & $5(4.2)$ \\
\hline \multicolumn{4}{|c|}{$\begin{array}{l}\text { PASS } 2 \text { = patient acceptable symptom state; SD = standard deviation. } \\
\text { *Unless indicated otherwise. } \\
\text { †Data available for } 52 \text { new referrals and } 190 \text { new consults. } \\
\text { †Data available for } 53 \text { new referrals and } 190 \text { new consults. }\end{array}$} \\
\hline
\end{tabular}

Table 3), indicating a substantial societal burden of costs in knee OA across the continuum of care, irrespective of the outcome of consultation (surgery or not). The distribution of direct and indirect costs was comparable across all stages of care (Figure 2, Figure 3 and Figure 4). The largest proportion of mean total costs was attributed to productivity losses $(79 \%$ at first consult, $82 \%$ at the presurgical appointment and $83 \%$ at the long-term follow-up). Overall, the greatest costs were incurred at 1.5 months after TKA by the health care payer and the patient or private insurer (\$7346 and $\$ 7310$, respectively), reflecting the costs of acute care and early postoperative rehabilitation. Specifically, a substantial proportion of the economic burden of TKA comprised indirect costs resulting from patient productivity losses $(40 \%)$ and caregiver assistance (37\%), with $10 \%$ allocated for out-of-pocket expenditures for supplies and equipment (primarily assistive walking devices, raised toilet seats and ice packs) and 4\% for medications not covered by the public health care system.

\section{Health-related quality of life}

Mean HRQoL scores were similar for patients at the time of referral, at the initial surgical consultation and at the preadmission appointment (Table 4). Overall, patients experienced an improvement in health status postoperatively, reporting higher EQ-5D, SF-12 and WOMAC scores at the one-year follow-up (Table 4). 


\begin{tabular}{|c|c|c|c|}
\hline \multirow[b]{2}{*}{ Nonoperative treatment } & \multicolumn{3}{|c|}{ No. (\%) of patients; ${ }^{*}$ stage } \\
\hline & $\begin{array}{c}\text { Prereferral } \\
n=248^{\dagger}\end{array}$ & $\begin{array}{c}\text { Presurgery } \\
n=119\end{array}$ & $\begin{array}{c}\text { Long-term } \\
\text { follow-up } \\
n=14\end{array}$ \\
\hline Physiotherapy & $123(49.6)$ & $40(33.6)$ & $7(50.0)$ \\
\hline Recommended but opted out & $11(4.4)$ & $1(0.8)$ & 0 \\
\hline Chiropractic therapy & $17(6.9)$ & $6(5.0)$ & $1(7.1)$ \\
\hline Recommended but opted out & $1(0.4)$ & 0 & 0 \\
\hline Occupational therapy & $7(2.8)$ & $4(3.4)$ & $1(7.1)$ \\
\hline Recommended but opted out & 0 & 0 & 0 \\
\hline Massage therapy & $33(13.3)$ & $9(7.6)$ & $2(16.0)$ \\
\hline Osteopathy & $8(3.2)$ & $1(0.8)$ & $1(7.1)$ \\
\hline Acupuncture & $18(7.3)$ & $7(5.9)$ & $0(4.0)$ \\
\hline Pedorthist or orthotist services & $57(23.0)$ & $14(11.8)$ & $1(7.1)$ \\
\hline Intra-articular joint injections & $142(57.3)$ & $33(27.7)$ & $2(14.3)$ \\
\hline Corticosteroid & $122(49.2)$ & $29(24.4)$ & $1(7.1)$ \\
\hline Hyaluronic acid & $37(14.9)$ & $1(0.8)$ & 0 \\
\hline Unknown & $10(4.0)$ & $2(1.7)$ & $1(7.1)$ \\
\hline Other & $2(0.8)$ & 0 & 0 \\
\hline Recommended but opted out & $12(4.8)$ & $1(0.8)$ & $1(7.1)$ \\
\hline Weight loss & $53(21.4)$ & $34(28.6)$ & $5(35.7)$ \\
\hline No. of kg lost, mean $\pm \mathrm{SD}$ & $9.1 \pm 9.7$ & $6.1 \pm 5.9$ & $7.2 \pm 6.4$ \\
\hline Exercise & $176(71.0)$ & 92 (77.3) & $8(57.1)$ \\
\hline Aerobic & $128(51.6)$ & $75(63.0)$ & $5(35.7)$ \\
\hline Resistance & $88(35.5)$ & 39 (32.8) & $4(28.6)$ \\
\hline Stretching & $116(46.8)$ & $67(56.3)$ & $3(21.4)$ \\
\hline Other & $4(1.6)$ & 0 & $2(14.3)$ \\
\hline Activity modification & $201(81.0)$ & $93(72.8)$ & $7(50.0)$ \\
\hline Gait aid & $92(37.1)$ & $52(43.7)$ & $5(35.7)$ \\
\hline Topical NSAID & $183(73.8)$ & $70(58.8)$ & $4(28.6)$ \\
\hline Knee sleeve or brace & $105(42.3)$ & $42(35.3)$ & $4(28.6)$ \\
\hline Specialized footwear & $76(30.6)$ & 32 (26.9) & $4(28.6)$ \\
\hline Oral medications & $209(84.3)$ & 107 (89.9) & $7(50.0)$ \\
\hline NSAIDs & $143(57.7)$ & $79(66.4)$ & $4(28.6)$ \\
\hline Analgesics & $169(68.1)$ & 70 (58.8) & $2(14.3)$ \\
\hline Steroids & $6(2.4)$ & $8(6.7)$ & $1(7.1)$ \\
\hline Antirheumatoid agents & $5(2.0)$ & $3(2.5)$ & 0 \\
\hline Other & $22(8.9)$ & $24(20.2)$ & 0 \\
\hline
\end{tabular}

\section{Proportion of nonoperative referrals}

Of the 232 newly referred patients, 138 (60\%) were scheduled for TKA following their initial consultation. The remainder of the cases were deemed nonoperative, with inadequate nonoperative management and insufficient OA severity identified by surgeons as the primary reasons for this decision for $35 \%$ of the cases. When asked before their first orthopedic consult, a subset of patients reported being unwilling to undergo surgery $(8 \%)$ or being unsure $(10 \%)$. These patients most frequently provided the following reasons: a belief that other nonoperative management options were still available (28\%), a need for more information about treatment options $(22 \%)$, insufficient symptoms $(20 \%)$ and an interest in possibly undergoing TKA in the future $(20 \%)$.

\section{Discussion}

The escalating societal costs of knee OA underscore the need for innovative and sustainable strategies to reduce wait times without compromising the quality of patient care. By providing the first point of contact, PCPs play a central role in the diagnosis and nonoperative management of knee OA, as well as in the judicious selection of patients who may benefit from surgery. Our findings are consistent with previous studies that showed substantial evidence-topractice gaps in the primary care management of knee 


\begin{tabular}{|c|c|c|c|c|c|c|c|c|}
\hline \multirow[b]{3}{*}{ Stage of care } & \multicolumn{3}{|c|}{ Health care payer perspective } & \multicolumn{3}{|c|}{ Patient and private insurer perspective } & \multicolumn{2}{|c|}{ Societal perspective } \\
\hline & \multicolumn{2}{|l|}{ Cost, \$CAD } & \multirow[b]{2}{*}{$\begin{array}{c}\% \text { of } \\
\text { total cost }\end{array}$} & \multicolumn{2}{|c|}{ Cost, \$CAD } & \multirow[b]{2}{*}{$\begin{array}{c}\% \text { of } \\
\text { total cost }\end{array}$} & \multicolumn{2}{|c|}{ Total cost, \$CAD } \\
\hline & Mean \pm SD & $\begin{array}{l}\text { Median } \\
\text { (IQR) }\end{array}$ & & Mean \pm SD & $\begin{array}{l}\text { Median } \\
\text { (IQR) }\end{array}$ & & Mean \pm SD & Median (IQR) \\
\hline $\begin{array}{l}\text { Initial consult } \\
(n=231)\end{array}$ & $116.48 \pm 184.04$ & $\begin{array}{c}76.48 \\
(118.78)\end{array}$ & 6.8 & $1598.39 \pm 3675.87$ & $\begin{array}{c}242.57 \\
(1113.86)\end{array}$ & 93.2 & $1714.87 \pm 2910.44$ & $\begin{array}{c}414.30 \\
(1128.96)\end{array}$ \\
\hline $\begin{array}{l}3 \text { mo after consult } \\
(n=127)\end{array}$ & $105.00 \pm 198.91$ & $\begin{array}{c}42.60 \\
(154.40)\end{array}$ & 3.8 & $2635.97 \pm 6677.55$ & $\begin{array}{c}279.51 \\
(1535.87)\end{array}$ & 96.2 & $2740.98 \pm 6684.52$ & $\begin{array}{c}417.80 \\
(1615.65)\end{array}$ \\
\hline $\begin{array}{l}6 \text { mo after consult } \\
(n=93)\end{array}$ & $103.86 \pm 203.66$ & $\begin{array}{c}36.03 \\
(154.40)\end{array}$ & 4.2 & $2318.86 \pm 4642.18$ & $\begin{array}{c}431.00 \\
(1891.03)\end{array}$ & 95.8 & $2422.73 \pm 4677.75$ & $\begin{array}{c}505.45 \\
(2130.84)\end{array}$ \\
\hline $\begin{array}{l}9 \text { mo after consult } \\
(n=52)\end{array}$ & $65.41 \pm 98.56$ & $\begin{array}{l}33.30 \\
(83.39)\end{array}$ & 2.6 & $2589.05 \pm 5513.81$ & $\begin{array}{c}485.82 \\
(2024.21)\end{array}$ & 97.4 & $2615.69 \pm 5484.18$ & $\begin{array}{c}515.13 \\
(2045.97)\end{array}$ \\
\hline $\begin{array}{l}12 \text { mo after consult } \\
(n=20)\end{array}$ & $841.09 \pm 2226.33$ & $\begin{array}{c}64.58 \\
(142.14)\end{array}$ & 15.0 & $4735.09 \pm 10454.90$ & $\begin{array}{c}499.39 \\
(3765.48)\end{array}$ & 85.0 & $5576.17 \pm 10785.96$ & $\begin{array}{c}562.53 \\
(5153.33)\end{array}$ \\
\hline $\begin{array}{l}\text { Presurgery } \\
(n=141)\end{array}$ & $299.58 \pm 82.35$ & $\begin{array}{l}262.45 \\
(80.83)\end{array}$ & 12.6 & $2085.37 \pm 5033.54$ & $\begin{array}{c}122.54 \\
(838.32)\end{array}$ & 87.4 & $2384.94 \pm 5055.13$ & $\begin{array}{c}461.39 \\
(864.55)\end{array}$ \\
\hline $\begin{array}{l}1.5 \text { mo after surgery } \\
(n=85)\end{array}$ & $7346.24 \pm 288.71$ & $\begin{array}{r}7269.91 \\
(81.60)\end{array}$ & 50.1 & $7310.24 \pm 8879.38$ & $\begin{array}{l}12453.66 \\
(8528.38)\end{array}$ & 49.9 & $14656.48 \pm 8838.40$ & $\begin{array}{l}12453.66 \\
(8528.38)\end{array}$ \\
\hline $\begin{array}{l}6 \text { mo after surgery } \\
(n=57)\end{array}$ & $208.42 \pm 957.91$ & $\begin{array}{c}64.80 \\
(129.98)\end{array}$ & 15.5 & $1146.92 \pm 3254.51$ & $\begin{array}{c}59.31 \\
(506.79)\end{array}$ & 84.5 & $1355.35 \pm 3598.62$ & $\begin{array}{l}219.42 \\
(592.28)\end{array}$ \\
\hline $\begin{array}{l}9 \text { mo after surgery } \\
(n=41)\end{array}$ & $244.74 \pm 1154.54$ & $\begin{array}{l}24.05 \\
(94.16)\end{array}$ & 15.4 & $1603.61 \pm 4691.87$ & $\begin{array}{l}195.31 \\
(614.00)\end{array}$ & 84.6 & $1848.35 \pm 4819.13$ & $\begin{array}{l}241.70 \\
(896.86)\end{array}$ \\
\hline $\begin{array}{l}12 \text { mo after surgery } \\
(n=18)\end{array}$ & $138.52 \pm 328.40$ & $\begin{array}{c}45.87 \\
(123.41)\end{array}$ & 5.1 & $2579.53 \pm 4446.37$ & $\begin{array}{c}143.31 \\
(2573.62\end{array}$ & 94.9 & $2718.05 \pm 4646.69$ & $\begin{array}{c}244.79 \\
(2743.32)\end{array}$ \\
\hline $\begin{array}{l}\text { Long-term follow-up } \\
\text { (no surgery) }(n=14)\end{array}$ & $816.58 \pm 2699.44$ & $\begin{array}{c}78.00 \\
(176.76)\end{array}$ & 10.6 & $1228.30 \pm 2371.09$ & $\begin{array}{c}176.47 \\
(1657.89)\end{array}$ & 89.4 & $2044.88 \pm 3414.59$ & $\begin{array}{c}370.59 \\
(1938.54)\end{array}$ \\
\hline
\end{tabular}

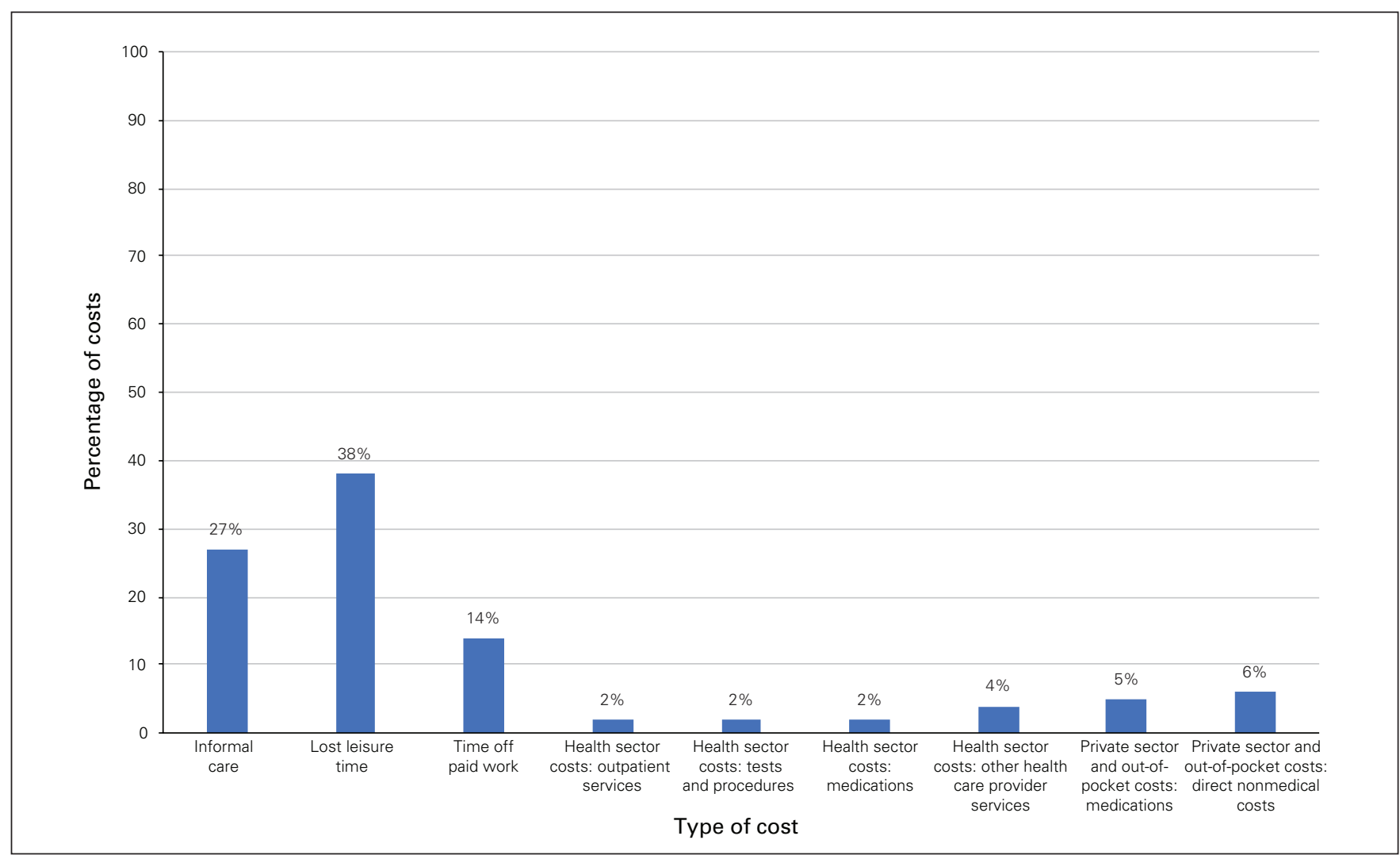

Fig. 2. Distribution of direct and indirect costs of knee osteoarthritis incurred by new referrals at their initial surgical consultation. Patients recalled costs over the last 3 months. 


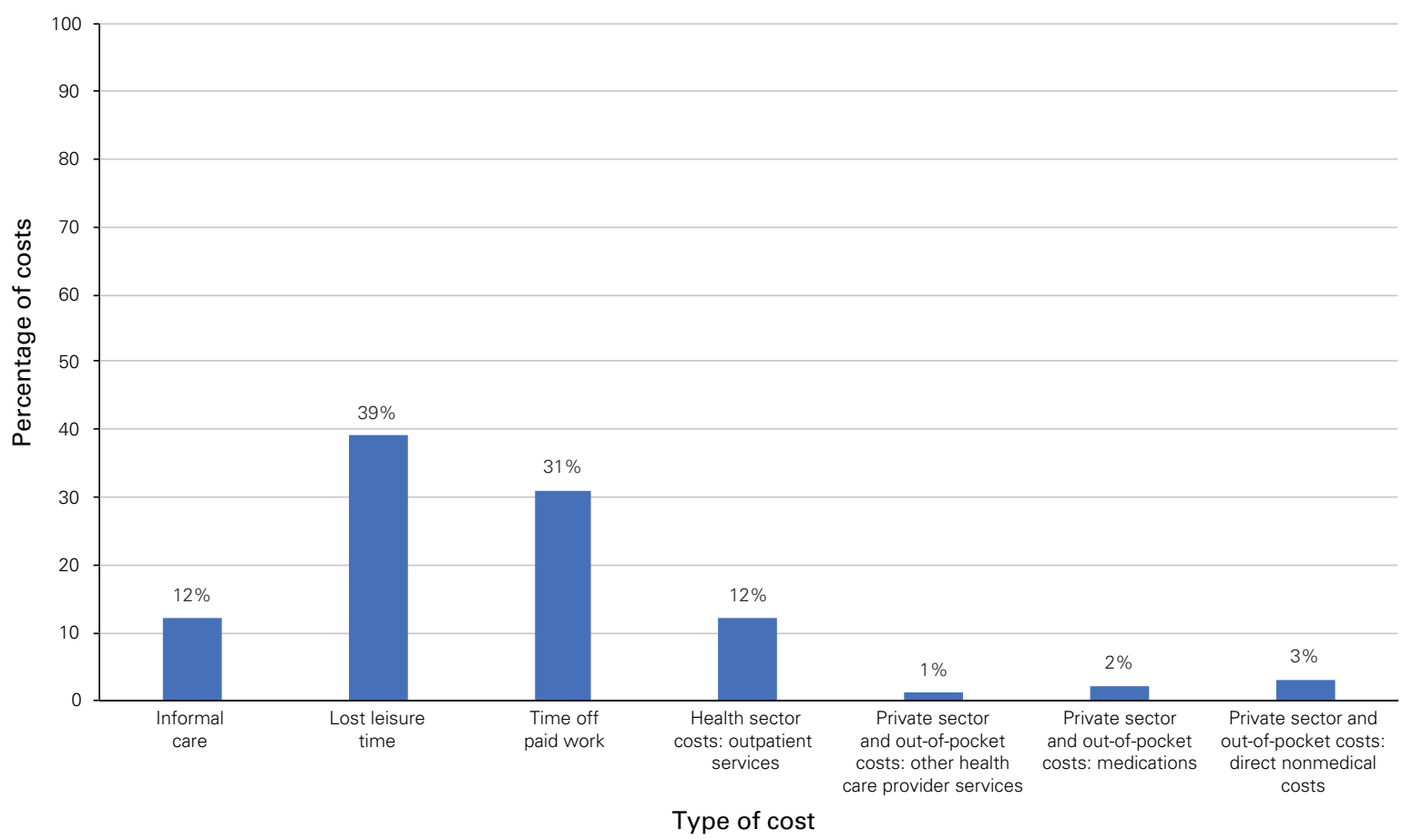

Fig. 3. Distribution of direct and indirect costs of knee osteoarthritis at the preadmission appointment before patients underwent total knee arthroplasty. Patients recalled costs over the last 3 months.

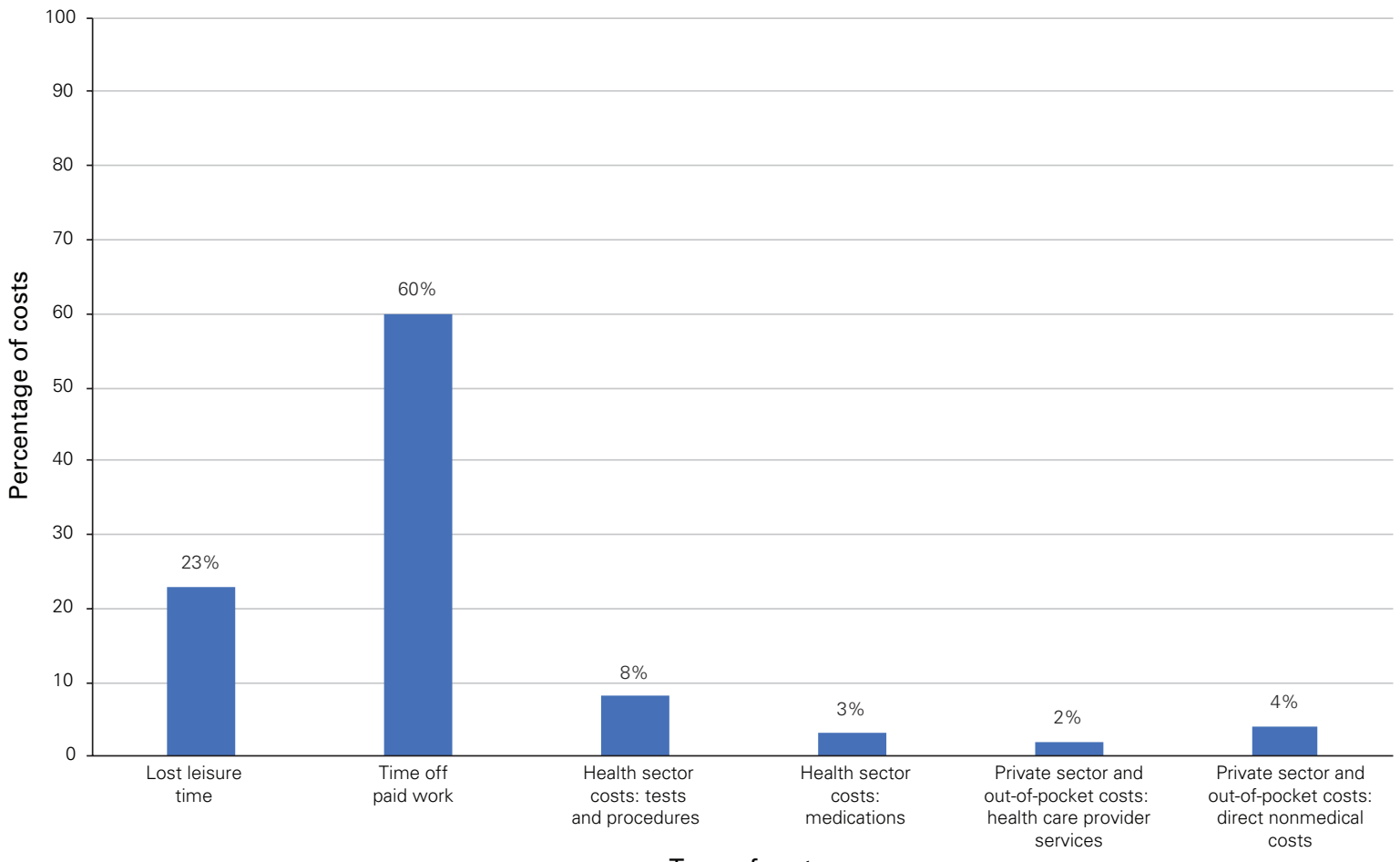

Type of cost

Fig. 4. Distribution of direct and indirect costs of knee osteoarthritis at the long-term follow-up. Patients in this group were deemed unsuitable candidates for total knee arthroplasty at their first consultation and had not pursued surgical treatment since. Patients recalled costs over the last 3 months. 


\begin{tabular}{l} 
Table 4. Health-related quality of life across different stages of care \\
\cline { 2 - 5 }
\end{tabular}

OA. ${ }^{21,43} \mathrm{We}$ found that nonoperative treatments were underused before referral, and the ordering of diagnostic imaging tests was not aligned with prominent clinical practice guidelines. Although MRI examinations are generally not indicated for the diagnosis of OA, $21 \%$ of patients reported undergoing prereferral MRI scans in our study. The ordering of unwarranted imaging tests, inadequate nonoperative management and the high rate of nonoperative referrals indicate a need for novel approaches to improve the primary care management of knee OA and streamline the screening of referrals.

This study captured a wide range of costs from multiple costing perspectives across a relevant time horizon. Our findings suggest that the impact of OA goes beyond the boundaries of the health care system, as more than $85 \%$ of the total costs incurred during WT2 were borne by the patient or their private insurer. Moreover, from the patient perspective, costs increased during WT2 because of growing productivity losses. This reveals the economic burden of knee OA and highlights its substantial impact on work productivity.

Previous studies measured changes in HRQoL during $\mathrm{WT}^{6}{ }^{6}$ and evaluated the effect of the presurgery waiting time on postoperative health status. ${ }^{8}$ However, they did not consider costs incurred during WT1, citing methodologic challenges in recruiting patients at the time of referral. Furthermore, contrary to the study by Ackerman and colleagues, ${ }^{6}$ who found that more than half of patients waiting for TKA experienced a deterioration in HRQoL, our results suggest that patient health status remains relatively stable throughout the waiting period. Other studies investigating the impact of waiting for TKA on postoperative outcomes have shown that prolonged presurgery wait times (longer than 6 and 9 mo) were associated with poorer SF-36, WOMAC and SF-12 scores at 6 and 12 months after surgery. ${ }^{8}$ This, coupled with the postoperative improvement in HRQoL observed in our study, suggests that shorter wait times would enable patients to achieve a higher quality of life sooner.
Overall, our findings underscore the need for better primary care management of patients considering TKA and offer valuable information regarding the current state of wait times, referral, nonoperative treatment and the cost burden for patients awaiting surgery. The overarching goal of this program of research is to develop a novel online platform to improve the management of patients with knee OA. Our vision is to offer a comprehensive online platform that will provide referring physicians with guidance on diagnostic imaging, nonoperative treatment and the optimal timing and criteria for referral; a suite of educational and postoperative resources for patients; and streamlined access to allied health providers who can offer care for patients with OA who are considering or who have undergone TKA.

To illustrate our plans for implementation, we developed a conceptual model of our proposed online platform that demonstrates key stakeholders, intended outcomes and key components (Figure 5). Our vision is that the online system would start with referring physicians indicating if they are diagnosing a patient with knee OA or managing a patient whom they have already diagnosed. If they indicate a new diagnosis we would provide relevant diagnostic criteria and red flags for inflammatory arthritis or other arthropathies for physicians to consider in their differential diagnosis. Next, we would outline appropriate imaging for physicians to order as a baseline for measuring radiographic disease severity. From there, physicians would indicate patient characteristics such as age, comorbidities and previous treatments trialed. The online algorithm would then provide tailored feedback regarding appropriate avenues to explore with their patients and streamlined access to allied health professionals in their community who could facilitate this care. The system could also suggest relevant patient educational materials via an online link that providers could share with their patients. For patients who had exhausted nonoperative treatment options, the system could provide links to preoperative educational 


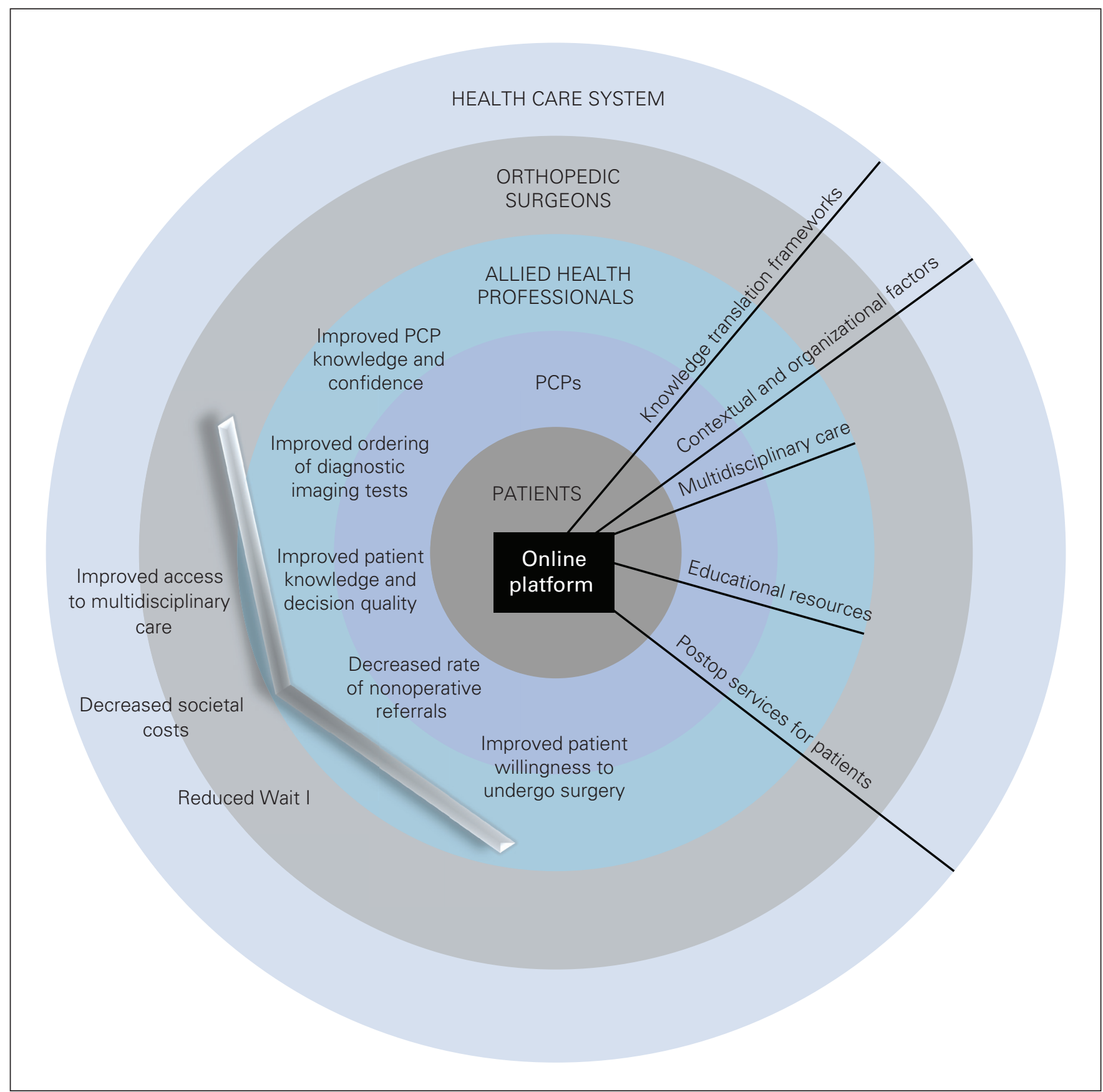

Fig. 5. Conceptual model of our proposed online platform intended to offer a cost-effective solution to improve the quality of care for patients with osteoarthritis of the knee. PCP = primary care provider; WT1 = wait time from referral to initial surgical consulation.

resources to help them prepare for surgery. If this model is to be sustainable and effective, it will require ongoing refinement and engagement with end users including patients, physicians, orthopedic surgeons and allied health professionals.

\section{Limitations}

This study has several limitations. Similar to researchers who have previously conducted research in this field, ${ }^{6,8}$ we were unable to reach approximately $30 \%-$ $50 \%$ of participants at each 3-month follow-up for prospective data collection, which decreased the precision of the estimates. However, attrition was largely attributed to appointment postponements or cancellations or an insufficient follow-up period. Our study was unable to account for revision TKA because of a relatively short follow-up period. As is inherent in any study relying on patient-reported health care resource use, a further limitation is the possibility of recall bias. 
An optimal recall period has not been established, although current best evidence suggests recall of salient events such as hospital admissions may be accurate over longer time frames, while more common events such as family physician appointments and medication use may be accurately recalled over a much shorter time period. ${ }^{44-47}$ Thus, we asked our study patients to report any health care resource use every 3 months to help minimize the chance of recall bias. Finally, a small number of patients $(n=20)$ included in our cost estimations had a 1-year wait time, which may reflect patient preference to delay surgery. However, on the basis of the current wait times at our centre (approximately 12-14 mo after the initial consult is booked) we believe that this group is worth capturing to get an accurate representation of the full spectrum of waiting. Our cost estimations may be inflated compared with those of centres with shorter wait times. Thus, the generalizability of our findings to other settings is unclear. However, our conclusions about the importance of capturing costs from multiple perspectives along the continuum of care are relevant outside our context.

\section{Conclusion}

The rising demand for TKA, coupled with the economic burden of OA and detrimental health outcomes of excessive wait times, calls for the development of new models of care. This study provides insight into the shortcomings of current primary care management of knee OA and emphasizes the importance of developing interventions that target both patients and referring providers. Given the variety of wait time management strategies that have been proposed and implemented across Canada, the evaluation of alternative clinical pathways is a much-needed focus for future research efforts. Subsequent studies will determine the costeffectiveness of our online educational platform and identify strategies to promote user engagement.

Affiliations: Health and Rehabilitation Sciences Program, Western University, London, Ont. (Lebedeva); School of Physical Therapy, Western University, London, Ont. (Churchill, Marsh, Bryant); Fowler Kennedy Sport Medicine Clinic, London, Ont. (Churchill, Giffin); Division of Orthopaedic Surgery, Schulich School of Medicine and Dentistry, Western University, London, Ont. (MacDonald, Giffin); University Hospital, London Health Sciences Centre, London, Ont. (MacDonald); Department of Health Research Methods, Evidence, and Impact, McMaster University, Hamilton, Ont. (Bryant).

Competing interests: S. MacDonald reports receiving personal fees from DePuy Synthes and holding stock or stock options from Hip Innovations Technology, JointVue, CurvaFix, Parvizi Surgical Innovation, Smith \& Nephew and Stryker, outside the submitted work. No other competing interests were declared.

Contributors: All authors conceived the article. K. Lebedeva and L. Churchill acquired the data, which K. Lebedeva, J. Marsh, S. MacDonald and D. Bryant analyzed. K. Lebedeva and D. Bryant drafted the manuscript, which K. Lebedeva, L. Churchill, J. Marsh and
S. MacDonald and R. Giffin critically revised. All authors gave final approval of the version to be published.

Content licence: This is an Open Access article distributed in accordance with the terms of the Creative Commons Attribution (CC BYNC-ND 4.0) licence, which permits use, distribution and reproduction in any medium, provided that the original publication is properly cited, the use is noncommercial (i.e., research or educational use), and no modifications or adaptations are made. See: https://creativecommons. org/licenses/by-nc-nd/4.0/

\section{References}

1. Medical Advisory Secretariat. Total knee replacement: an evidencebased analysis. Ont Health Technol Assess Ser 2005;5(9):1-51.

2. Barua B. Waiting your turn: wait times for bealth care in Canada. Vancouver: Fraser Institute; 2017. Available: www.fraserinstitute. org/sites/default/files/waiting-your-turn-2017.pdf (accessed 2018 Mar. 1).

3. Statistics Canada. Age and sex highlight tables, 2016 census. 2016. Available: http://www12.statcan.gc.ca/census-recensement/2016/dp-pd/ hlt-fst/as/Table.cfm?Lang=E\&T=11 (accessed 2018 Jan. 5).

4. Losina E, Thornhill TS, Rome BN, et al. The dramatic increase in total knee replacement utilization rates in the United States cannot be fully explained by growth in population size and the obesity epidemic. 7 Bone 7t Surg Am 2012;94:201-7.

5. Ravi B, Croxford R, Reichmann WM, et al. The changing demographics of total joint arthroplasty recipients in the United States and Ontario from 2001 to 2007. Best Pract Res Clin Rheumatol 2012; 26:637-47.

6. Ackerman IN, Bennell KL, Osborne RH. Decline in health-related quality of life reported by more than half of those waiting for joint replacement surgery: a prospective cohort study. BMC Musculoskelet Disord 2011;12:108.

7. Desmeules F, Dionne CE, Belzile ÉL, et al. The impacts of presurgery wait for total knee replacement on pain, function and healthrelated quality of life six months after surgery. 7 Eval Clin Pract 2012;18:111-20.

8. Lizaur-Utrilla A, Martinez-Mendez D, Miralles-Muñoz FA, et al. Negative impact of waiting time for primary total knee arthroplasty on satisfaction and patient-reported outcome. Int Orthop 2016;40:2303-7.

9. Perruccio AV, Davis AM, Hogg-Johnson S, et al. Importance of selfrated health and mental well-being in predicting health outcomes following total joint replacement surgery for osteoarthritis. Artbritis Care Res (Hoboken) 2011;63:973-81.

10. Fortin PR, Penrod JR, Clarke AE, et al. Timing of total joint replacement affects clinical outcomes among patients with osteoarthritis of the hip or knee. Arthritis Rheum 2002;46:3327-30.

11. Judge A, Arden NK, Cooper C, et al. Predictors of outcomes of total knee replacement surgery. Rheumatology 2012;51:1804-13.

12. March L, Cross M, Tribe K, et al. Cost of joint replacement surgery for osteoarthritis: the patients' perspective. 7 Rheumatol 2002;29:1006-14.

13. Gupta S, Hawker GA, Laporte A, et al. The economic burden of disabling hip and knee osteoarthritis (OA) from the perspective of individuals living with this condition. Rheumatology 2005;44:1531-7.

14. DiBonaventura MD, Gupta S, McDonald M, et al. Impact of selfrated osteoarthritis severity in an employed population: crosssectional analysis of data from the national health and wellness survey. Health Qual Life Outcomes 2012;10:30.

15. Hunter DJ, Schofield D, Callander E. The individual and socioeconomic impact of osteoarthritis. Nat Rev Rheumatol 2014; 10:437-41.

16. Centre for Spatial Economics, Canadian Medical Association. The economic cost of wait times in Canada. Milton: Centre for Spatial Economics; 2008. 
17. Damani Z, Mackean G, Bohm E, et al. Insights from the design and implementation of a single-entry model of referral for total joint replacement surgery: critical success factors and unanticipated consequences. Health Policy 2018;122:165-74.

18. Canadian Institute for Health Information. Wait times for priority procedures in Canada, 2017. Ottawa; 2017. Available: www.cihi.ca/ sites/default/files/document/wait-times-report-2017_en.pdf (accessed 2018 Mar. 1)

19. Wait Time Alliance. Time to close the gap: report card on wait times in Canada. Wait Time Alliance; 2014. Available: www.waittimealliance. ca/wp-content/uploads/2014/06/FINAL-EN-WTA-Report-Card.pdf (accessed 2018 Mar. 1).

20. Jevsevar DS. Treatment of osteoarthritis of the knee: evidence-based guideline, 2nd edition. 7 Am Acad Orthop Surg. 2013;21(9):571-6.

21. Klett M-J, Frankovich R, Dervin GF, et al. Impact of a surgical screening clinic for patients with knee osteoarthritis: a descriptive study. Clin 7 Sport Med 2012;22:274-7.

22. McHugh GA, Campbell M, Luker KA. GP referral of patients with osteoarthritis for consideration of total joint replacement: a longitudinal study. Br 7 Gen Pract 2011;61:e459-68.

23. Zhang W, Moskowitz RW, Nuki G, et al. OARSI recommendations for the management of hip and knee osteoarthritis, Part II: OARSI evidence-based, expert consensus guidelines. Osteoarthritis Cartilage 2008;16:137-62.

24. Coyte PC, Hawker G, Croxford R, et al. Variation in rheumatologists' and GPs' perceptions of indications for and outcomes of TKA. f Rheumatol 1996;23:730-8.

25. Toronto Athroplasty Research Group Writing Committee; Wright JG, Hawker GA, Hudak PL, et al. Variability in physician opinions about the indications for knee arthroplasty. 7 Arthroplasty 2011; 26:569-75.e1.

26. Waugh EJ, Badley EM, Borkhoff CM, et al. Primary care physicians' perceptions about and confidence in deciding which patients to refer for total joint arthroplasty of the hip and knee. Osteoarthritis Cartilage 2016;24:451-7.

27. Federal-Provincial-Territorial First Ministers. A 10-year plan to strengthen health care. Ottawa: Health Canada; 2004. Available: www.canada.ca/en/health-canada/services/health-care-system/health -care-system-delivery/federal-provincial-territorial-collaboration/ first-ministers-meeting-year-plan-2004/10-year-plan-strengthen-health -care.html (accessed 2018 Jan. 5).

28. Canadian Medical Association. Streamlining patient flow from primary care to specialty care: a critical requirement for improved access to specialty care [policy]. Ottawa: Canadian Medical Association; 2014. Available: http://policybase.cma.ca/dbtw-wpd/policypdf/pd15-01. pdf (accessed 2018 Mar. 1).

29. Pomey MP, Clavel N, Amar C, et al. Wait time management strategies for total joint replacement surgery: sustainability and unintended consequences. BMC Health Serv Res 2017;17:629.

30. Lopatina E, Damani Z, Bohm E, et al. Single-entry models (SEMs) for scheduled services: towards a roadmap for the implementation of recommended practices. 2017;121:963-70.
31. Churchill LK. A model to reduce the proportion of inappropriate referrals to surgery for patients with osteoarthritis: a pilot study [thesis]. London (ON): University of Western Ontario; 2013.

32. Roos EM, Klässbo M, Lohmander LS. WOMAC osteoarthritis index. Scand F Rheumatol 1999;28:210-5.

33. McConnell S, Kolopack P, Davis AM. The Western Ontario and McMaster Universities Osteoarthritis Index (WOMAC): a review of its utility and measurement properties. Arthritis Rheum 2001;45:453-61.

34. Harris K, Dawson J, Gibbons E, et al. Systematic review of measurement properties of patient-reported outcome measures used in patients undergoing hip and knee arthroplasty. Patient Relat Outcome Meas 2016;7:101-8.

35. Cheak-Zamora NC, Wyrwich KW, McBride TD. Reliability and validity of the SF-12v2 in the medical expenditure panel survey. Qual Life Res 2009;18:727-35.

36. Ministry of Health and Long-Term Care. Schedule of benefits: physician services under the Health Insurance Act (effective March 1, 2016). Toronto: Ministry of Health and Long-Term Care; 2016.

37. Canadian Institute for Health Information. Patient cost estimator. Ottawa: Canadian Institute for Health Information; 2017. Available: www.cihi.ca/en/patient-cost-estimator (accessed 2017 Jan. 10).

38. Ministry of Health and Long-Term Care. Community physiotherapy clinic services: selection of transfer payment recipients. Toronto: Ministry of Health and Long-Term Care; 2013.

39. Ontario Health Insurance Plan. Ontario Drug Benefit Formulary. Toronto: Ministry of Health and Long-Term Care; 2018. Available: www.formulary.health.gov.on.ca/formulary/ (accessed 2018 Mar. 1).

40. Drummond MF, Schulpher MJ, Claxton K, et al. Methods for the economic evaluation of health care programmes. 4th ed. Oxford: Oxford University Press; 2015.

41. Statistics Canada. Average usual hours and wages by selected characteristics, monthly, unadjusted for seasonality. Ottawa: Statistics Canada; 2018. Available: https://www150.statcan.gc.ca/t1/tbl1/en/ tv.action?pid=1410032002 (accessed 2018 May 15).

42. Ministry of Labour, Training and Skills Development. Minimum wage rates in Ontario. Toronto: Ministry of Labour, Training and Skills Development; 2018. Available: www.ontario.ca/document/ your-guide-employment-standards-act-0/minimum-wage\#section-0 (accessed 2018 June 20).

43. Snijders GF, Den Broeder AA, Van Riel P, et al. Evidence-based tailored conservative treatment of knee and hip osteoarthritis. Scand $\mathcal{F}$ Rheumatol 2011;40:225-31.

44. Kjellsson G, Clarke P, Gerdtham U-G. Forgetting to remember or remembering to forget: a study of the recall period length in health care survey questions. 7 Health Econ 2014;35:34-46.

45. Thorn JC, Coast J, Cohen D, et al. Resource-use measurement based on patient recall. Appl Health Econ Health Policy 2013;11:155-61.

46. Bhandari A, Wagner T. Self-reported utilization of health care services: improving measurement and accuracy. Med Care Res Rev 2006; 63:217-35

47. Evans C, Crawford B. Patient self-reports in pharmacoeconomic studies. Pharmacoeconomics 1999;15:241-56. 